and partly on the observation that Hox gene expression in the hind limb bud resembles more closely that of the adjacent trunk mesoderm than does that of the fore limb bud ${ }^{1,3}$; Tabin and Laufer seek corroboration from Ahlberg's discussion ${ }^{4}$ of coelacanth median (and caudal) fin symmetry, and the earliest record of neartetrapod limb-like fragments 5 .

The continuous lateral fin-fold theory lacks support from living and fossil organisms, and the use of such hypothetical ancestral archetypes is ultimately incompatible with the continuity of evolutionary change $^{6}$. Apparent lateral fin folds in actual fossil jawless fishes are either restricted to specialized lineages ${ }^{7}$ or occur in conjunction with pectoral fins (osteostracans), questioning an ancestordescendant relationship between the two structures $^{8}$. The numerous inter-girdle spines of climatiid acanthodians (a group of early jawed fishes), long held as evidence of the continuous fin-fold, now appear to be a derived specialization ${ }^{9,10}$.

There is no evidence to support the theory that the pelvic appendage antedates the pectoral ${ }^{3}$. A recent review of agnathan interrelationships ${ }^{7}$ suggests that the pectoral fin evolved before any other component of the appendicular skeleton (thus exemplifying the role of fossil data in challenging the validity of decisions concerning the polarity of neontological data ${ }^{9}$ ). The earliest known pelvic fin skeletons from members of the main vertebrate groups consist of diminutive or abbreviated reiterations of the pectoral pattern $9,11,12$. The strong dissimilarity suggested by Tabin and Laufer is not found.

An alternative hypothesis sketched out in the figure could account for the actual patterns of morphology in the fossil record without recourse to theoretical ancestors, and for patterns of gene expression in embryology without the ectopic initiation of a new pectoral signalling centre. It may also incorporate more easily the phylogenetic history of the fourfold expansion of the Hox network occurring between invertebrates and tetrapods ${ }^{13}$. Greater similarity between the expression patterns in the hind limb bud and adjacent axial mesoderm than between the corresponding anterior tissue domains could result

1. Tabin, C. \&Laufer, E. Nature 361, 692-693 (1993).

2. Akam, M., Dawson, I. \& Tear, G. Development (Suppl.) 123-133 (1988)

3. Tabin, C. Development 116, 289-296 (1992).

4. Ahlberg, P. E. Nature 358, 459 (1992).

5. Ahlberg, P. E. Nature 354, 298-301 (1991)

5. Ahlberg, P. E. Nature 354, 298-301 (1991).
6. Rowe, T. \& Gauthier, J. Syst. Biol. 41, 372-378(1992).

7. Forey, P. \& Janvier, P. Nature 361, 129-134 (1993).

8. Forey, P.J. Vert. Paleont. 4, 330-343 (1984).

9. Maisey, J. G. Cladistics 2, 201-256 (1986).

10. Long, J. A. Zool. J. Linn. Soc. 87, 321-339 (1986).

11. Zangerl, R. Chondrichthyes I. Handbook of

Paleoichthyology (ed. Schultze, H.-P.) 3A (Fischer, Stuttgart, 1981).

12. Carroll, R. L. Vertebrate Paleontology and Evolution (Freeman, New York, 1988)

13. Holland, P. Bio Essays 14, 267-273 (1992).

14. Hornbruch, A. \& Wolpert, L. Development 111, 725-731 (1991). simply from the dynamic sequence of ontogenetic (and phylogenetic) development. Like the general anterior-toposterior gradient of vertebrate development, the occurrence of pectoral before pelvic appendages could be interpreted as phylogenetic recapitulation, just as the earliest jawed and jawless fishes tend to consist of elaborate brain cases and gill arches with only poorly differentiated axial and tail skeletons.

\section{Mike Coates}

University Museum of Zoology,

Downing Street,

Cambridge CB2 3EJ, UK

SIR - Tabin and Laufer ${ }^{1}$ present a thought-provoking model for the evolution of the tetrapod limb, but nevertheless leave untackled some important issues.

First, it has long been known that the axial level of the paired appendages of fishes is plastic, in that the specific level of origin of the fins has moved rostrally and/or caudally along the body axis during phylogeny. Therefore, there is no $1: 1$ correspondence between segment identity and the anterior-posterior point of developmental origin of the fins (see refs 2 , $3)$. If the Hox code of the posterior appendage reflects the level of origin of the fin from within the continuous primitive lateral fin fold, then clearly axial Hox code and appendage Hox code can become dislocated, both phylogenetically and ontogenetically. If the Tabin and Laufer model is correct, then such dislocation is likely to have been a feature of not only the fin-to-limb transition but also of the radiative evolution which has resulted in such diversity of fin phenotype and axial position.

Second, in the three-stage model proposed, the key step is the acquisition of a 'posterior' Hox code by the anterior appendage. An explanation for how this might come about is fundamental to the model. It is suggested that the ectopic initiation, in the anterior appendage, of a signalling site such as the zone of polarizing activity, assumed to be formerly confined to the posterior appendage, could provide the means whereby a posterior appendage genetic programme (deploying Hox $D$ cluster genes) could be 'co-opted' for the development of the anterior appendage. Indeed, there is now good evidence that some vertebrate homeotic transformations are generated by posteriorization of the relevant Hox code, such that inappropriate expression of a posterior code at more anterior levels changes the positional identity of the structures that form at those levels to a posterior character ${ }^{4.5}$. However, the model proposed begs the question of what happens to the intermediate part of the continuous primitive fin fold and fails to address the issue of why the putative homeotic change at anterior levels of the fold involved acquisition of the most posterior code, rather than the Hox code characteristic of the intermediate part of the fin fold. As a corollary, we might ask what type of pectoral appendage did the original anterior Hox code specify and can we identify such a phenotype in the fossil record?

Third, any model addressing the problem of the fin-to-limb transition during evolution should acknowledge that mesenchyme in fins and limbs arises from different lineages ${ }^{6,7}$. The mesenchyme of the tetrapod limb is mesoderm-derived and forms the endoskeleton, whereas the mesenchyme of the (phylogenetically more ancient) fin bud is both mesodermand neural crest-derived, forming endoskeleton proximally and dermal skeleton distally. In terms of phenotypic evolution of the primitive lateral fin fold, and the fin-to-limb transition, the lineage derivation of the mesenchyme has important implications with regard to mechanisms invoked to explain these evolutionary events. For example, is skeletal pattern within the neural crest-derived (ecto) mesenchyme of the fin specified in a manner identical to the mesodermderived mesenchyme? Can we expect to find nested patterns of Hox $A$ and $D$ cluster genes in the distal mesenchyme of the fin bud comparable to those reported for the distal mesenchyme of the limb bud $^{8,9}$ ? Although the model proposed by Tabin and Laufer is not incompatible with this embryology, it will need to accommodate the mixed lineage derivation of the mesenchyme found in the appendages of non-tetrapod vertebrates.

To put the Tabin and Laufer model and the aforegoing discussion into some perspective, the existence of a primitive lateral fin fold in an ancestral form, although widely discussed, remains entirely hypothetical in the absence of any supporting evidence (palaeontological or biological). Nevertheless, we believe that the authors are correct in stressing the need for comparative studies on Hox gene expression using other systems, but urge that questions such as those raised here form an integral part of any such study.

\section{Peter Thorogood}

\section{Patrizia Ferretti}

DevelopmentalBiology Unit,

Institute of Child Health,

30 Guilford Street,

London WC1N 1EH, UK

1. Tabin. C. \& Laufer, E. Nature 361, 692-693 (1993)

2. Goodrich, E.S. Studies on the Structure and Development of Vertebrates (Macmillan, London, 1930).

3. de Beer, G. R. Homology: an Unsolved Problem (Oxford University Press, 1971)

4. Kessel, M. \& Gruss, P. Cell67, 89-104 (1991).

5. Lufkin. T. et al. Nature 359, 835-841 (1992).

6. Thorogood P in Developmental Patterning of the Vertebrate Limb (eds Hinchliffe, J. R. et al.) 347-354 (Plenum, New York, 1991)

7. Smith, M. M. \& Hall, B. K. Biol. Rev. 65, 277-374 (1990)

8. Dolle, P. et al. Nature 342, 767-772(1989)

9. Yokouchi, Y. et al. Nature 353. 443-445 (1991) 